\title{
Transition From Pediatric to Adult Care for Young Adults With Chronic Respiratory Disease
}

\author{
L Denise Willis
}

\author{
Introduction \\ Transition versus Transfer \\ Rationale for Transition \\ Condition-Specific Models of Transition \\ Barriers to Transition \\ Factors Associated With Successful Transition \\ Special Considerations \\ Six Core Elements of Transition \\ Respiratory Therapists' Role \\ Summary
}

\begin{abstract}
Advances in medicine and technology have led to improved survival rates of children with chronic respiratory disease such as cystic fibrosis, neuromuscular disease, and ventilator dependence. Survival into adulthood has created the need for adult specialists for conditions originating in childhood. Transition from pediatric to adult health care is a process that requires advanced planning and preparation and is not a one-time transfer event. Transition should be standard practice, but many children with special health care do not experience successful transition outcomes. Barriers to successful transition include lack of a standardized process, inadequate planning, and poor communication. Adverse outcomes have occurred in cases of abrupt or haphazard transfers. A successful transition process includes early introduction and ongoing discussion that engages the adolescent to plan and prepare for the eventual transfer of care. Care responsibilities should be gradually shifted from the parent to the adolescent in a manner appropriate for the adolescent's age and developmental status. Good communication and collaboration between pediatric and adult care teams is crucial to ensure a smooth transfer of care. Incorporating the 6 core elements of transition can be helpful in developing a successful transition program. This narrative review summarizes the literature for health care transition from pediatric to adult care including the rationale, barriers, factors associated with successful transition, and special considerations. The intent of this review is to increase clinician awareness of health care transitions and the components necessary for an effective transfer of young adults with chronic respiratory disease. Understanding the transition process is an important consideration for both pediatric and adult clinicians, including respiratory therapists. Key words: transition; transfer of care; pediatrics; adult-oriented care; special health care needs; cystic fibrosis; neuromuscular disease; cerebral palsy; ventilator-dependent. [Respir Care 2020;65(12):1916-1922. (C) 2020 Daedalus Enterprises]
\end{abstract}

\section{Introduction}

Advancements in medical care and technology have led to increased survival of children with special health care needs who, in the past, would not have lived into adulthood.
Children with special health care needs are defined as those who have an increased risk for chronic conditions and require health services beyond those normally required. ${ }^{1-3}$ This includes children with cystic fibrosis, neuromuscular disease, congenital heart disease, cerebral palsy, and 


\section{Transition From Pediatric to Adult Care in Chronic Respiratory Disease}

chronic ventilator dependence, and others who require the routine use of respiratory devices to maintain pulmonary stability. It has been estimated that $>9$ million children are considered to have special health care needs, and roughly 500,000 turn 18 y old each year. ${ }^{1}$

The improved survival of children with chronic illness has created the need for health care transition from pediatric to adult care for adolescents and young adults with special health care needs. Health care transition is defined as the purposeful and planned movement of young adults with chronic medical conditions from child-centered to adultoriented health care systems. ${ }^{4} \mathrm{~A}$ consensus statement regarding health care transitions for young adults with special health care needs reported that the goal of transition is to maximize lifelong functioning and potential through appropriate and uninterrupted services while moving from adolescence to adulthood. ${ }^{5}$

Transition from pediatric to adult care was established as a priority for children with special health care needs by the Maternal and Child Health Bureau in the Healthy People 2010 initiative..$^{5-7}$ Despite decades of work in this area, there has been little progress. ${ }^{8,9}$ A national survey of children with special health care needs revealed that the majority had not met transition outcome measures related to planning, and essentially no improvement occurred from 2005 to $2010{ }^{1,9,10}$ A survey of in-patient general pediatric services in U.S. children's hospitals showed that only $38 \%$ of respondents reported having transition initiatives. ${ }^{11}$ Additionally, in a study of 139 hospitalized adolescents and young adults $15-21$ y old, $<40 \%$ reported having received some form of transition preparation. ${ }^{12}$

Transition involves both primary care and specialty services. Medically complex children often have multiple specialists involved in their care. ${ }^{13}$ While physicians maintain a critical role in the transition process, it is important that all clinicians, including those on both the transferring (pediatric) and receiving (adult) sides, are informed about what medical transition entails. Respiratory therapists routinely care for both adult and pediatric patients with chronic conditions such as cystic fibrosis, neuromuscular disease, cerebral palsy, and similar diagnoses originating in childhood. While many therapists are not likely to be actively involved in the transition process, a basic understanding of health care transitions can help ensure a smoother transfer for young adult patients who move from pediatric to adult care.

Ms Willis is affiliated with Respiratory Care Services, Arkansas Children's Hospital, Little Rock, Arkansas.

Ms Willis has disclosed no conflicts of interest.

Correspondence: L Denise Willis MSc RRT RRT-NPS AE-C. E-mail: willisld@archildrens.org.

DOI: $10.4187 /$ respcare. 08260
This review summarizes the literature regarding health care transition from pediatric to adult care, including the difference between transition and transfer of care, the rationale and barriers, disease-specific models, and special considerations. Factors associated with successful transition and the 6 core elements are also discussed. The intent of this review is to increase awareness of the necessary components for an effective transition process. This information is applicable to both pediatric and adult clinicians who care for children and young adults with chronic respiratory disease.

\section{Transition versus Transfer}

It is crucial to note that health care transition is a process and not a one-time transfer event. ${ }^{7,13-18}$ The process involves careful planning and coordination leading up to the actual transfer of care. Good communication is key to avoid some of the potential pitfalls associated with haphazard transitions. This includes communication among the provider, the adolescent, and family as well as between the pediatric and adult providers. ${ }^{5,719}$ Poorly coordinated transitions have been associated with young adults with chronic conditions being lost to follow-up. ${ }^{20-22}$ Abrupt transfers may also lead to strained patient-provider relationships and mistrust. ${ }^{17,18}$ Lack of transition planning support is a challenge for both youth with special health care needs and those without, but children with special health care needs are at a higher risk for adverse outcomes from gaps in transition care. ${ }^{10,14,15,23}$ Failure to plan or inadequate transition planning may also result in young adults with chronic illness such as cerebral palsy or congenital heart disease to continue seeking care in pediatric facilities, which can have financial implications for these institutions. ${ }^{24,25}$

\section{Rationale for Transition}

Transitions are a normal part of life. Graduation, entering the workforce, marriage, and starting families all represent different types of life transitions. Transition to adult health care is no exception and should be presented as a positive event as children with special health care needs who previously did not survive are now becoming young adults. ${ }^{14}$ Planning for health care transitions should be standard for all adolescents and young adults regardless of their health care needs. ${ }^{23,26}$ Pediatric providers are typically not prepared to assist with concerns considered to be adult in nature, such as employment and reproductive issues, which are better addressed by adult clinicians. ${ }^{7,16,27}$ Depending upon disease severity and complexity, children with special health care needs often rely heavily on their parents and caregivers to provide and assist with their medical care at home. Throughout the transition process, adolescents should be engaged to begin learning self-management and 


\section{Transition From Pediatric to Adult Care in Chronic Respiratory Disease}

self-responsibility in preparation for eventually assuming their care or certain aspects of care when possible.,

\section{Condition-Specific Models of Transition}

In 1970, the median age of survival for a child with cystic fibrosis was $16 \mathrm{y} .{ }^{17} \mathrm{With}$ advances and improvements in medicine and technology, this median age has increased to $>40 \mathrm{y}^{29}$ Increased survival has elicited the need for adult providers specializing in cystic fibrosis care. The first adult cystic fibrosis programs in the United States were accredited by the Cystic Fibrosis Foundation in 1993, and by 2008 the Foundation required the majority of young adult patients to transfer to adult providers by 21 y of age. ${ }^{30}$ Transition programs are now considered standard for cystic fibrosis centers.

While cystic fibrosis programs have become a model of transition care for other diagnoses, transition programs for other conditions with pulmonary manifestations have not been as prevalent. A survey of pediatric pulmonology programs found that most did not utilize a standard transition process for ventilator-dependent patients, and many did not have a process in place. ${ }^{31}$ Unlike the consensus report for cystic fibrosis adult care, ${ }^{17}$ there are no published guidelines addressing transition of ventilator-dependent patients from pediatric to adult care. ${ }^{32}$ Although a consensus statement exists for transition of children with special health care needs, ${ }^{5}$ different chronic conditions bring unique disease-specific considerations that must be taken into account. For example, most young adults with cystic fibrosis will likely be able to assume responsibility for their care. However, that may not be the standard expectation for adolescents with cerebral palsy or other similar conditions depending on the severity of cognitive impairment. ${ }^{33-35} \mathrm{In}$ these instances, the parents often become legal guardians and remain involved in the young adult's care for the duration of their lifetime. ${ }^{33}$

\section{Barriers to Transition}

Many factors can influence the process of transition from pediatric care to adult health care. Differences between pediatric and adult care, education and training, changes in health insurance, degree of medical complexity, availability of services, and perceptions of the patient, family, and provider all have an impact on the course of transition. Other potential barriers to successful transfer include lack of transition planning, abrupt transfers, inadequate communication, and insufficient coordination of care.

There is some evidence to suggest that pediatric care and adult care embody 2 different medical subcultures. ${ }^{36}$ Pediatric health care is typically family-centered, whereas adult care tends to be patient-centered. ${ }^{30}$ Pediatric providers are accustomed to directing discussions to parents, while adult providers communicate directly with the adult patient. ${ }^{14}$ These differences in the culture of care may present challenges for parents and caregivers of children with special health care needs if they have not been prepared for this change or if they have not involved the adolescent in decision-making or encouraged self-management. Patients and families often develop strong ties and long-standing relationships with the pediatric clinicians who have been involved in their care for many years and may be reluctant to transfer services. ${ }^{14,27,37}$

Adult providers may be unfamiliar with many of the chronic conditions with a childhood onset and may not have received specialized training in providing care for young adults with these conditions. ${ }^{14,22,36}$ This has contributed to a lack of available adult providers and specialists who are experienced in caring for individuals with chronic illness originating in childhood. ${ }^{14,19,22}$ Studies evaluating resident and fellow physician training for transition care have indicated that very few received formal education and training for transition as part of the curriculum. ${ }^{38,39}$ It is unlikely that transition training is included in nursing or respiratory therapy programs, but it is an important consideration in caring for both adult and pediatric patients with chronic conditions with childhood origins.

Continuation of health insurance coverage has been an ongoing issue in health care transitions, but this has improved somewhat in the last decade. The Affordable Care Act and Medicaid expansion were both instrumental in ensuring better access to care and reducing gaps in coverage. ${ }^{40}$ The provision of coverage through age 25 and the elimination of preexisting condition exclusions were key factors in improving care access. However, Medicaid coverage and benefits vary by state. Resources, services, and support accessible by children with special health care needs may not be offered to young adults and could have an impact on availability of durable medical equipment, medications, and home nursing services. ${ }^{32}$

Clearly, the most evident barrier to successful health care transition is not having a process. Sudden and unexpected transfers of care have resulted in significant issues in young adults with chronic illness such as being lost to follow-up or forgoing care, poor adherence, and increased hospitalization. ${ }^{19-22}$ Some cases of abrupt transitions have been precipitated by crisis events such as pregnancy and nonadherence or meeting milestones such as high school graduation. ${ }^{15,41}$ There is a difference between eligibility for transition and readiness. ${ }^{19}$ Meeting age criteria for transition does not necessarily indicate readiness to transfer. Readiness requires advance planning and preparation. Preparation and planning are vital to ensure a smooth transfer from pediatric to adult care and to provide a positive experience for all involved, including providers and clinicians. 


\section{Transition From Pediatric to Adult Care in Chronic Respiratory Disease}

Table 1. Health Care Transition Timeline

\begin{tabular}{cccccc}
\hline \hline & & & Age & & \\
\cline { 2 - 5 } & 12 & 14 & 16 & 18 & $18-22$ \\
\hline Event & $\begin{array}{c}\text { Introduction to transition } \\
\text { policy }\end{array}$ & $\begin{array}{c}\text { Begin transition } \\
\text { planning }\end{array}$ & $\begin{array}{c}\text { Prepare for adult care model } \\
\text { and discuss transfer }\end{array}$ & Transition to adult care model & Transfer care
\end{tabular}

Adapted from Got Transition (available at: https://gottransition.org).

\section{Factors Associated With Successful Transition}

While there are multiple attributable causes of failed transitions, components of care can be implemented to promote an organized and coordinated transition process. Recommendations vary for when to begin discussions regarding eventual transition to adult care and range from age 12 to 14 y., ${ }^{5,19,22,26,42}$ It is never too early to begin planning for the future. Introducing the idea of transition sooner rather than later allows time for acceptance and preparation. Some transition models for cystic fibrosis have suggested introducing the concept around the time of diagnosis to help set the expectation of surviving into adulthood and becoming independent. ${ }^{17,18,29}$ Table 1 includes recommendations for a transition timeline.

Providers and clinicians should engage adolescents in their care as developmentally appropriate. ${ }^{4,19,26}$ Adolescents with chronic respiratory disease should be knowledgeable about their condition and be involved in decisions that impact their care. Transition planning should be a shared responsibility of the care team, the patient, and parents. Care responsibilities can be gradually shifted to the adolescent as suitable for age and development. ${ }^{18}$ Initial tasks could involve identifying medications and treatments and can progress to understanding the purpose of each one. ${ }^{18}$ Adolescents who require aerosol or airway clearance therapies could learn to administer their own therapies if they are physically and intellectually able to do so. Eventually the adolescent might begin to address the care team directly with input from parents when needed. ${ }^{18}$ Self-management should be encouraged to foster eventual independence. ${ }^{7}$

Communication between the pediatric and adult care team is vital to the success of transition. ${ }^{5,19,41}$ Good communication facilitates collaboration and coordination of care. The pediatric provider should prepare and maintain a medical health summary that is portable, accessible, and involves the adolescent and family. ${ }^{5,19,28,41}$ This summary provides crucial information about the young adult patient to the adult providers and promotes collaboration between care teams. ${ }^{5}$

Utilization of a transition service coordinator or patient navigator can enhance the success of transition programs and facilitate a seamless transfer of care. ${ }^{17,43-45}$ The role of the coordinator is to ensure that the transition plan is created and to assist with scheduling the initial adult outpatient clinic appointment. ${ }^{17}$ One pediatric institution has reported having a multi disciplinary consultation service to coordinate transition care for medically complex patients. ${ }^{46}$ Having a dedicated individual or team assigned to assist with the transition process can help minimize gaps in service. Through personal experience in a pediatric out-patient pulmonary clinic, respiratory therapists have played key roles in the transition process for patients with cystic fibrosis, neuromuscular disease, chronic ventilator dependence, and other chronic respiratory conditions by coordinating care with adult pulmonary clinics.

Having a medical home has been associated with an increased probability that children with special health care needs receive transition planning and preparation. ${ }^{1,9,10}$ The concept of the medical home is to provide comprehensive primary care for those with special health care needs. ${ }^{13}$ This approach provides an ideal environment to deliver coordinated care that incorporates transition planning.

There are several key points regarding the transfer of care event to keep in mind, including interim care and transfer follow-up. The pediatric team should ensure there are enough prescriptions and supplies to last until the first adult appointment. If the young adult becomes acutely ill or experiences other issues after the last planned visit with the pediatric provider but before scheduled evaluation with the adult provider, the pediatric care team should be available to address those needs. Follow-up from the pediatric side with both the adult clinic and the young adult should also occur to ensure the appointment was attended and to assist the adult team with any questions they may have.

\section{Special Considerations}

Transfer of care should ideally occur between the ages of 18 and $21 \mathrm{y}^{26}$ However, there are special circumstances that must be considered. Visits with the adult provider should not occur during times of acute illness; initial evaluations are best done during times of medical stability to begin establishing new relationships. Adolescents in endstage disease or who are actively dying should not undergo the transition process and should remain with the pediatric team throughout those difficult situations. ${ }^{29}$ 


\section{Transition From Pediatric to Adult Care in Chronic Respiratory Disease}

Table 2. Six Core Elements of Transition

\begin{tabular}{|c|c|}
\hline Element & Description \\
\hline Transition policy & $\begin{array}{l}\text { Develop a policy with input from patients and } \\
\text { families } \\
\text { Ensure all staff are educated on policy and } 6 \text { core } \\
\text { elements } \\
\text { Introduce policy to patients and families beginning } \\
\text { at age } 12\end{array}$ \\
\hline $\begin{array}{r}\text { Tracking and } \\
\text { monitoring }\end{array}$ & $\begin{array}{l}\text { Establish criteria and procedure for identifying } \\
\text { adolescents ready to begin transition process } \\
\text { Utilize a flow sheet or registry to track progress }\end{array}$ \\
\hline $\begin{array}{l}\text { Transition } \\
\text { readiness }\end{array}$ & $\begin{array}{l}\text { At age } 14 \text {, begin performing regular transition } \\
\text { readiness assessments } \\
\text { Identify needs and discuss goals for self-care }\end{array}$ \\
\hline $\begin{array}{l}\text { Transition } \\
\text { planning }\end{array}$ & $\begin{array}{l}\text { Update readiness assessments, goals, and medical } \\
\text { summary } \\
\text { Prepare for adult-care approach beginning at age 18, } \\
\text { including legal considerations for decision- } \\
\text { making, privacy, and consent } \\
\text { Discuss timing of transition } \\
\text { Assist with identifying adult providers }\end{array}$ \\
\hline Transfer of care & $\begin{array}{l}\text { Plan transfer during a time of medical stability } \\
\text { Transfer records to adult care team } \\
\text { Communication between pediatric and adult } \\
\text { providers }\end{array}$ \\
\hline $\begin{array}{l}\text { Transfer } \\
\text { completion }\end{array}$ & $\begin{array}{l}\text { Confirm that first appointment was attended } \\
\text { Collaborative partnership between pediatric and } \\
\text { adult care team }\end{array}$ \\
\hline
\end{tabular}

Adolescents with intellectual disabilities also represent unique considerations. ${ }^{30,33,34}$ While many young adults with chronic respiratory disease are able to live independently and manage their own care, there are a subset who will be unable to do so. In these situations, parents and caregivers remain involved to varying degrees in decision-making and providing care and are often appointed as legal guardians when necessary. ${ }^{33}$ The traditional transition process may look differently under these circumstances.

\section{Six Core Elements of Transition}

In collaboration with the Maternal and Child Health Bureau and The National Alliance to Advance Adolescent Health, the Got Transition Center for Health Care Transition Improvement was established (https://gottransition.org, Accessed June 11, 2020). Got Transition provides information and resources to help establish transition programs and processes, including the 6 core elements of transition: transition policy, tracking and monitoring, readiness assessment, transition planning, transfer of care, and transfer completion. These elements are not necessarily intended to be a model but rather to provide a customizable framework to implement transition processes. Details regarding what each element entails can be found in Table 2.

\section{Respiratory Therapists' Role}

While many respiratory therapists may not be directly involved in the transition process for young adults with chronic respiratory disease, a basic understanding of the rationale and concepts can be valuable for all clinicians. The role of the respiratory therapist continues to evolve as opportunities expand to out-patient clinics and other settings beyond in-patient units. Some therapists with specific responsibilities in cystic fibrosis or home ventilator programs have had the unique experience of assisting with transition and transfer of care. It is possible that respiratory therapists are underutilized in this area, and increased involvement could have a positive impact on transition outcomes.

Through personal experience as a previous out-patient coordinator of a pediatric home ventilator program, I had the opportunity to be involved in developing a transition program and supporting patients and families throughout the process. It was a humbling experience at times, and much knowledge was gained. All therapists and clinicians who work with young adults with chronic respiratory disease in any capacity are encouraged to become familiar with the institutional transition policy and procedures and to seek resources to learn more about health care transitions. It could mean the difference between a smooth and seamless process or a bumpy and fragmented transfer event.

\section{Summary}

Health care transition from pediatric care to adult-oriented care is a major life event for young adults with special health care needs. Transition is a process and not a onetime transfer of care event. Advanced planning and preparation are vital to ensuring a successful transition to adult care. Collaboration and communication between pediatric and adult care teams are essential components to promote a structured and organized transfer of care. Knowledge and education regarding transition processes is an important consideration for both adult and pediatric clinicians.

Although transition is not an entirely new concept, research and related outcomes are still relatively young as some institutions are only beginning to introduce transition programs and incorporate new processes. There are many future research and quality-improvement opportunities, such as comparison of transition models, development of training programs for clinicians, and establishment of standard practice guidelines. Health care transitions for young adults with chronic respiratory disease may also 


\section{Transition From Pediatric to Adult Care in Chronic Respiratory Disease}

represent new opportunities to increase the value of the respiratory therapist.

\section{REFERENCES}

1. Lotstein DS, McPherson M, Strickland B, Newacheck PW. Transition planning for youth with special health care needs: results from the national survey of children with special health care needs. Pediatrics 2005;115(6):1562-1568.

2. Scal P, Ireland M. Addressing transition to adult health care for adolescents with special health care needs. Pediatrics 2005;115(6):16071612.

3. Hergenroeder AC. The transition into adulthood for children and youth with special health care needs. Tex Med 2002;98(2):51-58.

4. Blum RW, Garell D, Hodgman CH, Jorissen TW, Okinow NA, Orr DP, Slap GB. Transition from child-centered to adult health-care systems for adolescents with chronic conditions: a position paper of the Society for Adolescent Medicine. J Adolesc Health 1993;14(7):570576.

5. American Academy of Pediatrics, American Academy of Family Physicians, American College of Physicians-American Society of Internal Medicine. A consensus statement on health care transitions for young adults with special health care needs. Pediatrics 2002;110 (6):1304-1306.

6. Sanders RA, Kuo DZ, Levey EB, Cheng TL. Transitioning adolescents to adult care and adulthood: is it time yet? Contemp Pediatr 2009;26(11):46-52.

7. McDonagh JE, Kelly DA. Transitioning care of the pediatric recipient to adult caregivers. Pediatr Clin North Am 2003;50(6):1561-1583.

8. Reiss J, Gibson R. Health care transition: destinations unknown. Pediatrics 2002;110(6 Pt 2):1307-1314.

9. McManus MA, Pollack LR, Cooley C, McAllister JW, Lotstein D, Strickland B, Mann MY. Current status of transition preparation among youth with special needs in the United States. Pediatrics 2013;131(6):1090-1097.

10. Lotstein DS, Ghandour R, Cash A, McGuire E, Strickland B, Newacheck P. Planning for health care transitions: results from the 2005-2006 national survey of children with special health care needs. Pediatrics 2009; 123(1):e145-e152.

11. Coller RJ, Ahrens S, Ehlenbach ML, Shadman KA, Chung PA, Lotstein D, et al. Transitioning from general pediatric to adult-oriented inpatient care: national survey of US children's hospitals. J Hosp Med 2018;13(1):13-20.

12. Dwyer-Matzky K, Blatt A, Asselin BL, Wood DL. Lack of preparedness for pediatric to adult-oriented health care transition in hospitalized adolescents and young adults. Acad Pediatr 2018;18(1):102-110.

13. Burdo-Hartman WA, Patel DR. Medical home and transition planning for children and youth with special health care needs. Pediatr Clin North Am 2008;55(6):1287-1297.

14. Callahan ST, Winitzer RF, Keenan P. Transition from pediatric to adult-oriented health care: a challenge for patients with chronic disease. Curr Opin Pediatr 2001;13(4):310-316.

15. Viner R. Transition from paediatric to adult care: bridging the gaps or passing the buck? Arch Dis Child 1999;81(3):271-275.

16. Madge $S$, Bryon $M$. A model for transition from pediatric to adult care in cystic fibrosis. J Pediatr Nurs 2002;17(4):283-288.

17. Yankaskas JR, Marshall BC, Sufian B, Simon RH, Rodman D. Cystic fibrosis adult care: consensus conference report. Chest 2004;125(1 Suppl):1S-39S.

18. West N, Mogayzel PJ. Transitions in health care: what can we learn from our experience with cystic fibrosis. Pediatr Clin North Am 2016;63(5):887-897.
19. Hergenroeder AC, Wiemann CM, Cohen MB. Current issues in transitioning from pediatric to adult-based care for youth with chronic health care needs. J Pediatr 2015;167(6):1196-1201.

20. Christie D, Viner R. Chronic illness and transition: time for action. Adoles Med State Art Rev 2009;20(3):981-987.

21. Sibanda D, Singleton R, Clark J, Desnoyers C, Hodges E, Day G, Redding G. Adult outcomes of childhood bronchiectasis. Int $\mathrm{J}$ Circumpolar Health 2020;79(1):1731059.

22. Mazur A, Dembinski L, Schrier L, Hadjipanayis A, Michaud PA. European Academy of Paediatric consensus statement on successful transition from paediatric to adult care for adolescents with chronic conditions. Acta Paediatr 2017;106(8):1354-1357.

23. Lebrun-Harris LA, McManus MA, Ilango SM, Cyr M, McLellan SB, Mann MY, et al. Transition planning among US youth with and without special health care needs. Pediatrics 2018;142(4):e20180194.

24. Goodman EM, Mendez E, Throop C, Ogata ES. Adult survivors of pediatric illness: the impact on pediatric hospitals. Pediatrics 2002;110 (3):583-589.

25. Lam P-Y, Fitzgerald BB, Sawyer SM. Young adults in children's hospitals: why are they there? Med J Aust 2005;182(8):381-384.

26. American Academy of Pediatrics, American Academy of Family Physicians, American College of Physicians, Transitions Clinical Report Authoring Group. Supporting the health care transition from adolescence to adulthood in the medical home. Pediatrics 2011;128(1):182-200.

27. Fox A. Physicians as barriers to successful transitional care. Int J Adolesc Med Health 2002;14(1):3-7.

28. Sanders RA, Kuo DZ, Levey EB, Cheng TL. Transitioning adolescents to adult care and adulthood: Is it time yet? Contemp Pediatr 2009;26(12):46-55.

29. Goralski JL, Nasr SZ, Uluer A. Overcoming barriers to a successful transition from pediatric to adult care. Pediatr Pulmonol 2017;52 (S48):S52-S60.

30. Okumura MJ, Kleinhenz ME. Cystic fibrosis transitions of care: lessons learned and future directions for cystic fibrosis. Clin Hest Med 2016;37(1):119-126.

31. Agarwal A, Willis D, Tang X, Bauer M, Berlinski A, Com G, et al. Transition of respiratory technology dependent patients from pediatric to adult pulmonology care. Pediatr Pulmonol 2015;50(12):1294-1300.

32. Cheng PC, Panitch HB, Hansen-Flaschen J. Transition of patients with neuromuscular disease and chronic ventilator-dependent respiratory failure from pediatric to adult pulmonary care. Paediatr Respir Rev 2020;33:3-8.

33. Herzer M, Goebel J, Cortina S. Transitioning cognitively impaired young patients with special health needs to adult-oriented care: collaboration between medical providers and pediatric psychologists. Curr Opin Pediatr 2010;22(5):668-672.

34. Berens J, Wozow C, Peacock C. Transition to adult care. Phys Med Rehabil Clin N Am 2020;31(1):159-170.

35. Binks JA, Barden WS, Burke TA, Young NL. What do we really know about the transition adult-centered health care? A focus on cerebral palsy and spina bifida. Arch Phys Med Rehabil 2007;88(8):1064-1073.

36. Reiss JG, Gibson RW, Walker LR. Health care transition: youth, family and provider perspectives. Pediatrics 2005;115(1):112-120.

37. Betz CL. Facilitating the transition of adolescents with chronic conditions from pediatric to adult health care and community settings. Issues Compr Pediatr Nurs 1998;21(2):97-115.

38. Sadun RE, Chung RJ, Pollock MD, Maslow GR. Lost in transition: resident and fellow training and experience caring for young adults with chronic conditions in a large United States academic medical center. Med Educ Online 2019;24(1):1605783.

39. Weeks M, Cole B, Flake E, Roy D. Resident and staff satisfaction of pediatric graduate medical education training on transition to adult care of medically complex patients. Mil Med 2018;183(11-12):e676e679. 


\section{Transition From Pediatric to Adult Care in Chronic Respiratory Disease}

40. Huang J, Porterfield SL. Changes in health insurance coverage and health care access as teens with disabilities transition to adulthood. Disabil Health J 2019;12(4):551-556.

41. Kripke C, Grumbach K. Transition to adult care for survivors of serious childhood illnesses and disabilities. Arch Pediatr Adolesc Med 2010;164(6):581-582.

42. White PH, Cooley WC, Transitions Clinical Report Authoring Group, American Academy of Pediatrics, American Academy of Family Physicians, American College of Physicians. Supporting the health care transition from adolescence to adulthood in the medical home. Pediatrics 2018;142(5):e20182587.
43. Rearick E. Enhancing success in transition service coordinators. Prof Case Manag 2007;12(5):283-287.

44. Dimitropoulos G, Morgan-Maver E, Allemang B, Schraeder K, Scott $\mathrm{SD}$, Pinzon J, et al. Health care stakeholder perspectives regarding the role of a patient navigator during transition to adult care. BMC Health Serv Res 2019;19(1):390.

45. Baines JM. Promoting better care: transition from child to adult services. Nurs Stand 2009;23(19):35-40.

46. Razon AN, Greenberg A, Trachtenberg S, Stollon N, Wu K, Ford L, et al. A multidisciplinary transition consult service: patient referral characteristics. J Pediatr Nurs 2019;47:136-141. 